\title{
A Comprehensive Approach to Investigating the Social Dimension in European Higher Education Systems-EUROSTUDENT and the PL4SD Country Reviews
}

\author{
Dominic Orr and Shweta Mishra
}

\section{Bologna Process and Social Dimension}

Reforms continue to embrace most higher education systems of the world and especially the 47 signatory states of the Bologna Declaration at the present. On average across the 28 OECD member countries for which data is available, spending in tertiary education in the period 1995-2011 has kept pace with the growth in student numbers - both showing a growth rate of around one quarter (Orr 2015). This impressive dynamic has been mirrored in many regions of the world and has turned the attention of policy-makers and higher education leaders to the questions of efficiency, effectiveness and equity of higher education provision. This means that they are interested in value for money, the impact of higher education and the question of impact on whom. Different countries have focused to a varying extent on these three issues, but they are evident in most policy documents and strategy papers. Starting with the Bologna Declaration in 1999, the Bologna Process has been a forum for common strategies. Greater harmonisation of degree structures, academic performance, quality assurance, and increased mobility for teachers and students have been central action lines (Dodds and Katz 2009, p. 4). Social dimension first entered the Bologna process in 2001 during the Prague communiqué and was further expanded and elaborated during the London communiqué (2007) and Leuven communiqué (2009). It has been defined as targeting 'participative equity' through a process of reform leading to the outcome that "the student body entering, participating in and completing higher education at all levels [reflects] the diversity of (...) populations" in the European Higher Education Area

D. Orr $(\square) \cdot$ S. Mishra

Deutsches Zentrum für Hochschul- und Wissenschaftsforschung (DZHW), Hannover,

Germany

e-mail: orr@dzhw.eu

S. Mishra

e-mail: mishra@dzhw.eu

(C) The Author(s) 2015

A. Curaj et al. (eds.), The European Higher Education Area,

DOI 10.1007/978-3-319-20877-0_30 
(London communiqué 2007). This is a long-standing goal of modern higher education systems, which aims to assure that educational success is detached from a person's origins. It is repeated in the most recent Bucharest communiqué of 2012 (p. 1). The aim can be morally argued from the standpoint of Rawls' (1971) argument for social justice. There is also an effectiveness argument for improving the participation and study conditions of certain groups of students, which was also made in the Leuven communiqué of 2009. It argues that available talent in Europe should be "maximised" to assure the realisation of a Europe of knowledge:

In the decade up to 2020 European higher education has a vital contribution to make in realising a Europe of knowledge that is highly creative and innovative. Faced with the challenge of an ageing population Europe can only succeed in this endeavour if it maximises the talents and capacities of all its citizens and fully engages in lifelong learning as well as in widening participation in higher education.

This argument has been further emphasised in the Bucharest communiqué of 2012 with reference to the challenges leading on from the economic and financial crisis (p. 1). These two arguments-social justice and effectiveness for a Europe of knowledge - provide the basis for efforts on the part of policy-makers at national and regional level, and leaders and practitioners in educational institutions to improve the social dimension of higher education. Their work is founded on the recognition that a confluence of three factors tend to determine educational success: student ability, material and immaterial (e.g. social and cultural) resources and opportunity. In particular, non-academic factors such as social background and aspiration, and study framework conditions (e.g. balance between work and studies) affect participation and success in higher education. Indeed, visible student ability may have been affected by a person's material and immaterial resources at a previous (e.g. secondary) educational level.

However, whilst the social dimension has been a focal point for the Bologna Process, at least since it was expressly defined as objective for the European Higher Education Area in 2007, it has been difficult to translate it into a manageable policy agenda. As recently stated in an analysis of this policy: "the social dimension is a policy item that found a way into the Bologna Process agenda, but could not grow into an implementable policy" (Orr et al. 2014; Yagci 2014). This is largely because concrete definitions are needed for the social dimension, but these are national-context specific and evolving. Indeed, Holford (2014, p. 22) has concluded: "the [social] dimension's limited success (and more recent displacement from policy, if not rhetoric) can be put down in large part to the difficulties of encapsulating complex and contested social priorities in internationally acceptable indicators (...)."

\section{Social Dimension-Unique Character}

The social dimension has a unique character as a policy issue, because it is very general and non-specific until it is related to a specific context. For this reason, it might be surprising to see it given such attention on the European level. Unlike the 
Bologna goals of system-level harmonisation or of promoting mobility between countries, social dimension is largely a national concern and improvements or otherwise in this area have effects on a national level. Even so, there are at least three reasons for the social dimension being seen as so central to European education policy:

European social model: This is seen as a distinguishing identifier of the European region in comparison to other geopolitical regions of the world (cf. European Commission 1994). It entails the goal of providing everyone an opportunity for educational betterment, who has the ability to profit from it. Although the EU does not have the mandate to actually enforce social policy, it aims to influence it through discussing policy frameworks and through using the Open Method of Coordination to enable policy learning between countries.

Direct competition with other regions of the world in a knowledge society: In a globalized world, the success of Europe is seen to depend on the maximum utilization of talent. One of the key factors for economic growth and successful competition with other regions is a well-educated population. The social dimension certainly has a role to play in promoting inclusive higher education, improving higher education attainment, and in reducing drop-out.

Education for keeping up with the pace of change in a global society: There is a recognition that increasingly skills and knowledge, once acquired, must be regularly refreshed (cf. EU 2006). This calls for more inclusion of older members of the population (often termed lifelong learning), which is also linked to the social dimension of higher education.

Despite being central to the European education policy, three specificities of this policy area create challenges for enabling policy learning. Firstly, any indicators related to social dimension of higher education call for data on students' (and potential students') character and biography, which are not frequently monitored e.g., migration and ethnicity, social background and educational pathway (European Commission 2014). Secondly, to ensure that higher education students represent the diversity in the student population, changes are needed at multiple levels - the school system, admission policies, entry routes, flexible study structures and provision for student support and counselling services. These involve working with multiple stakeholders and actors. Thirdly, it remains difficult to set clear overarching goals, which are appropriate for all countries and across topic areas. For instance, whilst the social dimension entails ensuring that there is equal representation of all social groups in all areas and fields of study, even this goal has to be somewhat nuanced. Some of the differences in fields of study, for instance, are common and may be largely based on personal choice (e.g. dominance of males in technical fields and women in linguistics), so that the goal of improvement for the social dimension would be to assure that nothing aside from personal preferences and ability was determining students' choice of field of study - but it is not to assure that half of all students in technical fields are women. 


\title{
3 Comprehensive Evaluation Approaches- EUROSTUDENT and PL4SD
}

\begin{abstract}
Although the social dimension has not been able to translate into an implementable policy item on the European level, the inclusion of social dimension in the Bologna Process has initiated discussions and debates on the underrepresentation of certain groups in higher education. Indeed, the social dimension could be reconceptualised, not as an implementation policy, but as an evaluative perspective on educational policy and practice.
\end{abstract}

Alongside the Bologna Process Implementation Report from 2012 and its forerunner from 2009 (Eurostat and Eurostudent 2009; Eurydice et al. 2012), a major source of data on aspects of studying related to the social dimension of higher education in international comparison has been the EUROSTUDENT project (Orr et al. 2011). The full set of EUROSTUDENT data covers the topics of demographics, including social background; access routes; study programs; accommodation, funding, and living costs; time use and employment during studies; and temporary mobility during studies. The data are drawn from harmonised national student surveys in more than 25 countries. In sum, the EUROSTUDENT data set provides a strong source of data on important aspects of student life in Europe within a comparative framework (Clancy 2010, p. 93). In this, EUROSTUDENT attempts to deal with the first problem of the social dimension mentioned above, i.e. provision of data suitable for indicators.

An alternative approach is to look closer not at the students, but at the whole education system and how it works for different student groups. This approach has been taken by the project Peer Learning for the Social Dimension (PL4SD). PL4SD is a three-year project (2012-2015) funded by the European Commission through the Lifelong Learning Programme (Erasmus Multilateral projects). ${ }^{1}$ The objective of the project is to provide policy-makers and practitioners with resources to develop effective measures for improving the social dimension of the European Higher Education Area. The instruments used to fulfil these goals are a database of policy measures and three national country reviews, which look at the combination of measures and processes in an education system and assess their appropriateness for improving the social dimension of higher education. Three Country Reviews were carried out in 2014. The approach of PL4SD recognises the second problem of the social dimension mentioned above, i.e. understanding how various levels of an education system and various stakeholders work together to influence learning opportunities and choice.

\footnotetext{
${ }^{1}$ www.pl4sd.eu.
} 


\section{Looking at the Way Learning Opportunities Are Allocated Within an Education System}

The EUROSTUDENT data set has shown that education systems work differently in the way they support and select students throughout their educational pathway. This becomes visible when looking at differences between student groups instead of focussing on the average student. In the 2008 publication from EUROSTUDENT, four "moments" of participative equity were highlighted (Orr et al. 2008). They are: before entry to higher education, at entry to higher education, study framework, and graduation and transition.

Each of the four moments contribute to the social dimension goals of raising aspirations, widening access, ensuring learning progress and improving retention and success, and lastly transitioning successfully into the labour market or to the next stage of higher education. These four moments are common to all education systems across Europe and we will now use data from EUROSTUDENT ${ }^{2}$ (Hauschildt et al. 2015) and insights from the project Peer Learning for the Social Dimension (PL4SD) to highlight their relevance to the social dimension. The PL4SD project collates initiatives used in European countries to support inclusion in higher education in an online databank. ${ }^{3}$ Additionally, it has carried out three Country Reviews to look in-depth at the four moments in the respective education systems and to investigate how the social dimension is being and could be further supported. ${ }^{4}$ The Country Reviews took place in two new EU member states and one non-member state - Croatia, Lithuania, and Armenia-each of which has been influenced by the work of the Bologna Process in recent reforms. ${ }^{5}$ At the same time, they are in the process of transitioning from an educational system, which particularly focuses on students' individual merit at school and university level, and much less on addressing students' collective needs.

\section{Before Entry to Higher Education}

This stage can generally be characterized as a qualifying and decision-making stage for students. EUROSTUDENT data highlights that students obtain access to higher education with different levels of qualifications. These include up to lower secondary, upper secondary academic track, upper secondary dual track, upper secondary vocational track and other national and foreign qualifications. Holders of the various pre-tertiary qualifications vary by personal and social characteristics.

\footnotetext{
${ }^{2}$ The full data set is available at http://www.database.eurostudent.eu.

${ }^{3}$ http://www.pl4sd.eu/index.php/database/about-the-database.

${ }^{4}$ http://www.pl4sd.eu/index.php/country-reviews/about-the-country-reviews.

${ }^{5}$ Country Reviews will be published summer 2015.
} 
While in most countries, the majority of students (63\%) hold an upper secondary academic track qualification, the share of students with higher education background, i.e. whose parents attained higher education themselves, leaving school via the 'golden route' of upper secondary academic track is particularly high compared to first generation students, whose parents did not attain higher education background (68 \% vs. $59 \%$ ). Conversely, many more students without higher education background hold an upper secondary vocational track qualification than students with higher education background (12\% vs. $8 \%$ ). Whilst the pre-tertiary level of the education system presents certain routes through the system that facilitate entry to higher education for prospective students, completion of a lower level of education leads to exiting this level and therefore entails a decision on the part of the learner as to whether they want to, aspire to or can enter higher education.

Even if graduates from both academic and vocational tracks have the chance to enter higher education, they still have to make a choice on whether to enter or not. In many cases, research has shown that students from underrepresented groups and their parents are less knowledgeable and in some cases more pessimistic about the options regarding participating in higher education. For this reason, one of the main goals for improving the equality of opportunities and the inclusivity of higher education is to make special efforts to prepare prospective students beforehand, providing them with information about the available options and raising their aspirations (Moore et al. 2013, p. 15). The PL4SD project has the role of seeking such interventions, which could be of interest to other countries looking into this issue. An example of such an initiative is from Newcastle University in Australia. The AIM High initiative focuses on supporting educational aspiration, attainment and access for students and families from low socio-economic backgrounds. This initiative is supported by the government programme "Higher Education Participation and Partnerships Program (HEPPP)" (OECD 2014, p. 5). A similar example is from Scotland funded by the Scottish Funding Council. The programme "Lothians Equal Access Programme for Schools" focuses on changing the culture in schools with low progression to higher education as a way of increasing social mobility (Lerpiniere 2013). In both of these cases, a national programme funded local initiatives - in a university in Australia or in a region of Scotland.

\section{At Entry to Higher Education}

This stage is characterised as the 'selection' stage of the higher education system. The entrance stage should ideally provide equal access opportunities to all prospective students. In order to understand this stage and its impacts it is therefore important to look at the general entry requirements for all groups of students. Regular entrance routes include upper secondary qualification or central higher education entrance examination. In the case of all three countries studied in the PL4SD Country Reviews, central entrance examinations have been introduced. The aim of these was to increase the transparency of the conditions of entry. At the same 
time, they lead to a very strict entrance route, especially as high scores in the examinations also provide access to state-funded study places.

Second chance routes are of particular interest, as these routes include remedial support to help prospective students including mature learners, who have not followed the typical path to higher education entry (Orr and Hovdhaugen 2014). EUROSTUDENT data collects information on the types of access routes to higher education in different countries and enables examination of the characteristics of the student body entering higher education through these access routes. The EUROSTUDENT project collects information mainly on four different types of alternative access routes. They are: upper secondary academic qualification through adult learning, special exam, special access courses, and accreditation/recognition of prior learning. At least 18 of the 29 countries in the EUROSTUDENT V data set offer one or a combination of different alternative access routes. Although the share of students utilising alternative access routes is small (on an average 3-8\%, varies by type of alternative access route), an examination of their characteristics is relevant to the social dimension. Students from previously underrepresented groups in higher education, such as those who delay their entry into higher education by more than 24 months after leaving school for the first time (delayed transition), mature, and first generation students tend to enter higher education via alternative routes more often than their counterparts.

\section{Study Framework}

This stage is characterised by progression towards the successful completion of studies within the higher education system. A central goal for the social dimension must be to ensure the retention and the learning progress of students regardless of their social and economic background. This ultimately means on one hand providing qualitative student support services, academic and career counselling, enabling a certain flexibility of study progress, and on the other hand ensuring direct support in the form of grants to achieving this objective.

Going to university or college involves costs for students-both general living and study costs. Therefore, the affordability of studies is an important issue. It is the question of how students can cover these costs and focus on their studies at the same time. Students tend to have rather different income levels, and these are made up from the central income sources, family contributions, own income and state support (Haaristo et al. 2011). State support is provided as a student grant or loan and is often envisaged as offering those students who need it the same financial circumstances as those who receive financial support from their parents. The EUROSTUDENT V data show that, on average, $42 \%$ of a student population can be assumed to be dependent on income from their parents, i.e. it makes up more than $50 \%$ of their monthly income. In contrast, only an average of $8 \%$ are dependent on state support, whilst $19 \%$ are dependent on earning their own income. These averages hide very large differences between countries, but they 
show that state support is usually highly targeted and that own income is an important source of funding for many students. In some countries including Finland and Estonia, but also Poland and Lithuania, the share of students dependent on this source of income is over one in five. This means that these systems are particularly likely to require more flexible study programmes in order for students to progress successfully through their studies, whilst balancing their work obligations. Whilst Finland does have such flexible programmes, Poland and Lithuania only have them for students, who are classified as part-time, often study in colleges rather than universities and are often required to pay fees. The new Universities Law from 2014 in Estonia now also regulates that students studying less than $75 \%$ of the set workload are classified as part-time and do not benefit from free study places, in contrast to full-time students. ${ }^{6}$ This may become a problem in a higher education system, where one third of students are financially dependent on their own earnings and around two-thirds assess their own situation during their studies as "I study alongside working". The discussions during the PL4SD Country Reviews also highlighted that many actors in higher education systems still envisage all students as young people fully focussed on their studies and nothing else.

Besides the questions of financial means and flexibility of programmes, which are rather concrete and easily understood, there is the issue of student support, to keep students on track during their studies and perhaps to help them better balance the demands of working and studying at the same time. During the PL4SD Country Review in Croatia, two of the big national universities presented their current initiatives to support students (Universities of Zagreb and Reika). In discussions, they highlighted one of the main problems was that this task was seen by academics at faculty level as not important - not an academic issue - and therefore externalised to the central level. What would be necessary would be a more integrated strategy, such as the one initiated in Finland by the National Students' Union (SYL 2013). In some countries, HEIs have adopted initiatives to help students by encouraging peer-to-peer support from other students, thereby cutting through any administrative or structural boundaries. An example is the Ludwig Maximillian University's peer-to-peer mentoring initiative, ${ }^{7}$ which is part-funded by a government programme in Germany. Each year around 800 first year students are assisted through this initiative.

\section{Graduation and Transition}

The graduation and transition stage is characterised as the move into the labour market or further educational training. Successfully offering a more inclusive higher education system necessitates consideration of what happens after completion of a

\footnotetext{
${ }^{6}$ https://www.riigiteataja.ee/en/eli/ee/Riigikogu/act/517062014007/consolide.

${ }^{7}$ http://www.p2pmentoring.peoplemanagement.uni-muenchen.de/index.html.
} 
course of study. Particularly in the context of higher youth unemployment in many countries affected by the financial crisis, there has been renewed interest in making sure that higher education assigns sufficient importance to the employability of students. In many countries, HEIs have introduced career centres in order to advise students on their opportunities after studying. At the same time, quality assurance regulations require labour market opportunities to be considered in the design of new study programmes.

The EUROSTUDENT V data set contains a comparative student assessment of chances on the labour market following a student's studies. It shows that around half of students currently assess their chances are good to very good, and around one fifth as poor to very poor. Whilst this is positive, it is noticeable that characteristics of students also affect these assessments-females are more pessimistic about their chances on the labour market than males, and first generation students more pessimistic than students whose parents attained higher education themselves (high educational background). Neither the PL4SD database nor the PL4SD Country Reviews showed any targeting of career centre measures by student group. However, the data suggest that this would also be necessary.

\section{Formative Evaluations of the Social Dimension as Possible Way Forward}

But what of the third problem mentioned above-i.e. defining clear overarching goals, which are appropriate for all countries and across topic areas. The final section on transition highlighted anew that a view of students as a diversified group, which has diverse needs for support, must continue throughout the higher education process. That is to say that it should not stop, for instance, at widening access to higher education. Since the diversity of students will be different and students will be studying within a different study framework in each country, and within a country in each type of higher education institution, it is very hard to conceive a supranational policy drive to support this.

Developing indicators on the social dimension of higher education would entail a thorough assessment of the students participating in the higher education system with regard to their abilities and characteristics. As discussed earlier, both quantitative expansion and efforts to create inclusive higher education systems have led to a more diversified student population, who are in many cases balancing work, studies, and other life duties. These changes are also driven by demographic change in many countries, where the typical age group of 18-24 years old is declining in the general population (Orr 2010). While the characteristics of the students body participating in higher education is changing, at the same it must be noted that the nature and extent of these changes differ between countries and also by higher education institutions. These differences demand a clear definition of different student groups for each country, and a distinction between 'regular' and 'new' student groups entering and participating in higher education. The students 
participating in higher education can be described on two main dimensions - their characteristics and abilities, and their study framework conditions.

Personal characteristics and abilities of the students can be described based on their age, gender, socio-economic conditions, race, ethnicity, migration background. Basically, these include a description of traits inherent to a student. On the other hand, study framework conditions include a description of external circumstances and settings that can facilitate or hinder students' higher education participation and completion. An example would be employment alongside studies. Employment is not something that a student is born with, but this can have a significant influence on their higher education attainment.

In addition to understanding the characteristics of the students, it is important to also evaluate the higher education systems that these students are part of. This is critical to understanding how higher education systems and their processes create mechanisms to widen participation and ensure completion of studies. This requires considering two key aspects - creating study conditions or remedial measures that facilitate participation and successful completion of education, and introducing system level and structural changes.

Remedial measures or study conditions often (but not always) facilitate higher education participation by taking into account students' personal characteristics and abilities and, for instance, provision of student support and counselling services, and increased funding opportunities for students from disadvantaged backgrounds. The second approach consists of introducing system level changes and structural level alterations. For instance, introducing alternative access routes to higher education, provision of flexible study programmes or short cycle programmes to enable certain student groups balance their work, personal, and educational life.

An inclusive and effective approach to the social dimension calls for a holistic focus encompassing students and the higher education system they study in. The scheme in Fig. 1 brings the students and higher education system together and emphasises the interaction between these two components. Very often the focus tends to be much more on the abilities and characteristics of the students and not so much on the interaction between students and various processes.

The definition of participative equity used since the London communique in 2007 has led to a focus on underrepresented groups, i.e. on persons, and only in a secondary step on processes. In other words, first the underrepresented group is defined and then the barriers for this group sought. This approach neglects the fact that diversity in terms of student groups, but also in terms of higher education provision has led to different ways of studying for both "underrepresented" and "well represented" groups of students. For instance, the EUROSTUDENT V data above showed that around one fifth of students have own earnings as a main source of income. Many of these students may be "new" students (e.g. older, from low social background etc.), but in some cases this is just a new way of studying.

Recognising this fact, the scheme above shows an overlap between the categories 'students' abilities and characteristics', on the one hand, and 'study framework', on the other. Indeed, the scheme highlights interactions between these and remedial and differentiation processes, whereby remedial and differentiation 


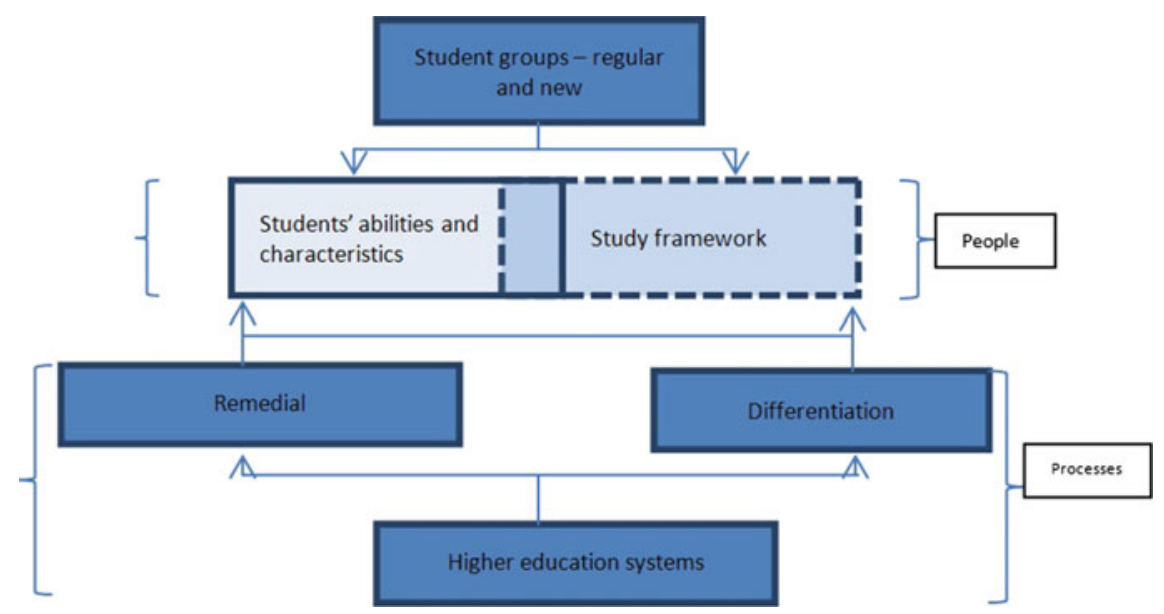

Fig. 1 A scheme for looking at the whole of higher education from a social dimension perspective. Source Authors

processes improve or worsen students' access or success by changing the interactions between students' abilities and characteristics and framework conditions.

This paper argues, therefore, against naïve summative evaluations based on oversimplified criteria, which are not helpful for policy learning. Instead, the task of a formative evaluation is to describe and analyse these remedial and differential processes. The Country Reviews from PL4SD are an early attempt to do this. If this could be done for multiple countries, the analyses could be used to identify clusters of national systems, which are organised in the same way and use the same supporting processes. Comparing survey data (e.g. from EUROSTUDENT) on a higher education system's student body and study framework within such a country cluster could provide insights into what is effective in a certain type of higher education system. That is to say that summative evaluation is possible but only when describing similar systems, i.e. following a kind of benchmarking approach made possible through formative evaluations.

Open Access This chapter is distributed under the terms of the Creative Commons Attribution Noncommercial License, which permits any noncommercial use, distribution, and reproduction in any medium, provided the original author(s) and source are credited.

\section{References}

Clancy, P. (2010). Measuring access and equity from a comparative perspective. In H. Eggins (Ed.), Access and equity. Comparative perspectives. The Netherlands: Sense Publishers.

Dodds, T., \& Katz, R. N. (2009). The Bologna process and the transformation of european higher education. Educause Center for Applied Research. Retrieved from https://net.educause.edu/ir/ library/pdf/ECS0905.pdf 
EU. (2006). Recommendation of the European parliament and of the council on key competences for lifelong learning. Official Journal of the European Union, (394/10). Retrieved from http:// eur-lex.europa.eu/LexUriServ/LexUriServ.do?uri=OJ:L:2006:394:0010:0018:en:PDF.

European Commission. (1994). European social policy - a way forward for the Union (White paper) (COM(94) 33 ed.). Retrieved from http://europa.eu/documentation/official-docs/whitepapers/pdf/social_policy_white_paper_com_94_333_a.pdf

European Commission, EACEA, \& Eurydice. (2014). Key Data on Early Childhood Education and Care in Europe. (2014 ed). Eurydice and Eurostat Report. Luxembourg: Publications Office of the European Union.

Eurostat, \& Eurostudent. (2009). The Bologna process in higher education in Europe-key indicators on the social dimension and mobility. Luxembourg: Eurostat.

Eurydice, Eurostat, \& Eurostudent. (2012). The European higher education area in 2012Bologna process implementation report. EACEA. Retrieved from http://www.ehea.info/ Uploads/(1)/BolognaProcessImplementationReport.pdf

Haaristo, H.-S., Orr, D., \& Little, B. (2011). The similarities and differences between students' income. Retrieved from http://www.eurostudent.eu/download_files/IB_Student_income_091211.pdf

Hauschildt, K., Gwosć, C., Netz, N., Mishra, S. (2015). Social and economic conditions of student life in Europe. In W. Bertelsmann Verlag (Ed.), Bielefeld and free online e-book. http://www. eurostudent.eu/download_files/documents/EVSynopsisofIndicators.pdf

Holford, J. (2014). The lost honour of the social dimension: Bologna, exports and the idea of the university. International Journal of Lifelong Education, 33(1), 7-25. doi:10.1080/02601370. 2013.873210

Lerpiniere, G. (2013). Lothians equal access programme for schools-strategic themes and impact (pp. 1-22). Retrieved from http://www.leapsonline.org/uploads/5/4/8/6/5486350/may_2013_ common_themes_and_impact_longterm_copy.pdf

Moore, J., Sanders, J., \& Higham, L. (2013). Literature review of research into widening participation to higher education. HEFCE. Retrieved from http://www.offa.org.uk/wp-content/ uploads/2013/08/Literature-review-of-research-into-WP-to-HE.pdf

OECD. (2014). Fostering equity in higher education compendium of practical case studiesforstering inclusion of disadvantaged students. OECD Publishing. Retrieved from http://www. oecd.org/edu/imhe/Fostering-inclusion-of-disadvantaged-students.pdf

Orr, D. (2010). Integrating an aging student population into higher education - challenges for evidence-based policy in Europe. Canadian Journal of Higher Education, 40(3), 25-42. Retrieved from http://www.ojs.library.ubc.ca/index.php/cjhe/article/view/2013

Orr, D. (2015). Intelligence brief: Spending on higher education in relation to growth in student numbers - an international comparison 2005-2011. doi: to come, Available online under https://www.researchgate.net/profile/Dominic_Orr/publication/273886424_IB-Spending_on_ HE_and_student_numbers_020315_Spending_on_higher_education_in_relation_to_growth_ in_student_numbers_2005-2011_an_international_comparison_using_the_OECD_data_set/ links/550f5bfc0cf21287416b0cf2.pdf?origin=publication_detail

Orr, D., \& Hovdhaugen, E. (2014). "Second chance" routes into higher education: Sweden, Norway and Germany compared. International Journal of Lifelong Education, 33(1), 45-61. doi:10.1080/02601370.2013.873212

Orr, D., Gwosc, C., \& Netz, N. (2011). Social and economic conditions of student life in Europe. In W. Bertelsmann (Ed.). Retrieved from http://www.eurostudent.eu/download_files/ documents/EIV_Synopsis_of_Indicators.pdf

Orr, D., Gwosć, C., \& Netz, N. (2014). Comment to the article "setting policy agenda for the social dimension of the Bologna process" by Yasemin Yagci (2014). Higher Education Policy. doi:10.1057/hep.2014.8

Orr, D., Schnitzer, K., \& Frackmann, E. (2008). Social and economic conditions of student life in Europe. W. Bertelsmann.

Rawls, J. (1971). A theory of justice. Cambridge: Harvard University Press.

SYL. (2013). Study ability through engagement-stimulating the development of academic communities. Retrieved from https://materiaalit.syl.fi/openfile.aspx?docid=3382

Yagci, Y. (2014). Setting policy agenda for the social dimension of the Bologna process. Higher Education Policy. doi:10.1057/hep.2013.38 